\title{
Assessment of new HDAC inhibitors for immunotherapy of malignant pleural mesothelioma
}

Douae Bensaid ${ }^{1,2}$, Thibaut Blondy ${ }^{1}$, Sophie Deshayes ${ }^{1}$, Virginie Dehame ${ }^{1}$, Philippe Bertrand ${ }^{3,4}$, Marc Grégoire ${ }^{1}$, Mohammed Errami ${ }^{2}$ and Christophe Blanquart ${ }^{1,45^{*}}$ (i)

\begin{abstract}
Background: Malignant pleural mesothelioma (MPM) is a very rare and highly aggressive cancer of the pleura associated in most cases with asbestos exposure. To date, no really efficient treatments are available for this pathology. Recently, it has been shown that epigenetic drugs, particularly DNA methylation or histone acetylation modulating agents, could be very efficient in terms of cytotoxicity for several types of cancer cells. We previously showed that a hypomethylating agent (decitabine) and a histone deacetylase inhibitor (HDACi) (valproic acid (VPA)) combination was immunogenic and led to the induction of an anti-tumor immune response in a mice model of mesothelioma. However, VPA is not very specific, is active at millimolar concentrations and is responsible for side effects in clinic. To improve this approach, we studied four newly synthetized HDACi, two hydroxamates (ODH and $\mathrm{NODH}$ ) and two benzamides (ODB and NODB), in comparison with VPA and SAHA. We evaluated their toxicity on immune cells and their immunogenicity on MPM cells in combination with decitabine.
\end{abstract}

Results: All the tested HDACi were toxic for immune cells at high concentrations. Combination with decitabine increased toxicity of HDACi only towards T-cell clone. A decrease in the proportion of regulatory $\mathrm{T}$ cells and natural killer cells was observed in particular with VPA and ODH. In MPM cells, all HDACi combinations induced NY-ESO-1 cancer testis antigen (CTA) expression and the recognition of the treated cells by a NY-ESO-1 specific T-CD8 clone. However, for MAGE-A1, MAGE-A3 and XAGE-1b mRNA expression, the results obtained depended on the HDACi used and on the CTA studied. Depending on the MPM cell line studied, molecules alone increased moderately PDL1 expression. When combined, a higher stimulation of this immune check point inhibitor expression was observed. Decitabine-induced anti-viral response seemed to be inhibited in the presence of HDACi.

Conclusions: This work shows that the combination of decitabine and HDACi could be of interest for MPM immunotherapy. However, this combination induced PD-L1 expression which suggests that an association with anti-PD-L1 therapy should be performed to induce an efficient anti-tumor immune response.

Keywords: Malignant pleural mesothelioma, HDAC inhibitors, Decitabine (5-aza-2'-deoxycytidine), Epigenetic drugs, Immunotherapy, Tumor antigen, CD8+ T-cell clone, PD-L1

\footnotetext{
* Correspondence: christophe.blanquart@inserm.fr

${ }^{1}$ CRCINA, INSERM, Université d'Angers, Université de Nantes, Nantes, France

${ }^{4}$ Réseau épigénétique du Cancéropôle Grand Ouest, Nantes, France

Full list of author information is available at the end of the article
}

(c) The Author(s). 2018 Open Access This article is distributed under the terms of the Creative Commons Attribution 4.0 International License (http://creativecommons.org/licenses/by/4.0/), which permits unrestricted use, distribution, and reproduction in any medium, provided you give appropriate credit to the original author(s) and the source, provide a link to the Creative Commons license, and indicate if changes were made. The Creative Commons Public Domain Dedication waiver (http://creativecommons.org/publicdomain/zero/1.0/) applies to the data made available in this article, unless otherwise stated. 


\section{Background}

Malignant pleural mesothelioma (MPM) is a deadly disease that develops in the pleura. It was confirmed by Wagner's studies that the vast majority of mesothelioma cases are actually attributed to asbestos exposure [1]. MPM was a very rare tumor before the industrial era; however, its incidence is increasing worldwide and is expected to peak in the year 2020. This cancer has an unusual molecular pathology with the loss of tumor suppressor genes being the predominant pattern of lesions [2]. Due to its resistance to all conventional therapies, the need for developing novel therapeutic regimens is urgent in order to cure this rare and treatment-resistant cancer.

In many cancers including mesothelioma, a hypermethylation of some gene promoters, including tumor suppressor genes (TSG) promoters, and overall DNA hypomethylation have been observed [3, 4]. Likewise, a decrease of acetylation of histones $\mathrm{H} 3$ and $\mathrm{H} 4$ was described $[5,6]$. Therefore, epigenetics based therapies could be an interesting opportunity to improve MPM treatment. It was shown in different cancers that the use of hypomethylating agents in combination or not with histone deacetylase inhibitors (HDACi) could be immunogenic [7-11]. It has been shown, in the laboratory and in another team, that MPM cell death induced by the combination of a hypomethylating agent/HDAC inhibitor could be immunogenic through the induction of tumor antigen expression especially cancer testis antigens (CTA) [12, 13]. Even if epigenetic drugs are efficient especially as a treatment of hematopoietic cancers such as leukemia, they display poor clinical benefits on solid tumors. Moreover, HDACi are unspecific and toxic to healthy cells. In addition, they have side effects such as hematologic toxicity, decreasing the number of platelets and leukocytes [14]. It is, therefore, necessary to develop new epigenetic drugs that are more specific, less toxic to healthy cells and specifically for immune cells, and that can act in low doses.

In order to identify more potent and more convenient HDACi for clinic, we tested four new HDACi we recently synthetized and characterized $[15,16]$. First of all, we evaluated the effect of these HDACi in comparison with valproic acid (VPA) and suberoylanilide hydroxamic acid (SAHA), two well-known HDACi, on total lymphocytes and on CD8+ T cell clones viability, and on some important populations of immune cells (natural killer (NK) and regulatory $\mathrm{T}$ (Treg) cells). Secondly, we tested the effect of the combination decitabine/new HDACi, in comparison with decitabine/VPA or SAHA combinations, on cancer testis antigens (CTA) expression, NY-ESO-1, MAGE-A1, MAGE-A3 and XAGE-1b, at the mRNA level in a malignant pleural mesothelioma cell lines. Indeed, CTA expression is associated with spontaneous antitumor immune responses and their discovery has led to the development of immunotherapy strategies and to antigen-specific cancer vaccines. Following treatment with decitabine/ HDACi combinations, recognition of MPM cells by a NYESO-1-specific CD8+ T-cell clone was assessed. PD-L1 mRNA expression, a molecule that is implicated in the major mechanism of immuno-suppression within the tumor microenvironment [17], was also measured. Recently, it was demonstrated that hypomethylating agent can induce interferon pathway through activation of endogenous retroviral elements in colorectal, breast, and ovarian cancer $[10,11]$. Therefore, the effect of the combinations was studied also on the mRNA expression of MDA5 (melanoma-differentiation-associated gene 5) and RIG-1 (retinoic-acid-inducible protein I), two essential immunoreceptors implicated in interferon signaling pathway and in RNA-sensing pathway.

\section{Methods}

\section{Cell culture}

The tumor cell lines used in this work were Meso96, Meso34, and Meso45, three human pleural mesothelioma cell lines, established from MPM patients' effusions obtained by thoracocentesis (the patient was informed and gave signed consent). The cell lines were characterized and cultured in our laboratory as described [18]. Cells were cultured in Roswell Park Memorial Institute (RPMI) 1640 medium supplemented with $10 \%$ heat-inactivated fetal calf serum, $2 \mathrm{mM}$ L-glutamine, $100 \mathrm{IU} / \mathrm{ml}$ penicillin, and $200 \mu \mathrm{g} / \mathrm{ml}$ streptomycin.

Lymphocytes were obtained from the clinical transfer platform (DTC, CIC-biothérapies Nantes) of Nantes Hospital (Nantes, France). CD8 T-cell clones used for this study, HLA-A*0201/NY-ESO-1(157-165)-specific CD8 T-cell clone was described previously [19].

\section{Drugs}

Decitabine (5-azaCdR) and VPA were purchased from Sigma-Aldrich (Saint-Quentin Fallavier, France). SAHA was from Interchim (Montluçon, France). HDACi ODB, $\mathrm{NODB}, \mathrm{ODH}$, and $\mathrm{NODH}$ were synthesized by Dr. Philippe Bertrand as described previously [15]. Structure of the HDACi is provided as Additional file 1: Table S1.

\section{Cell treatment}

For dose-response experiments, lymphocytes were seeded at $4 \times 10^{5}$ cells/well in RPMI $16408 \%$ HS in flat-bottomed 96-well plates, and CD8 T-cell clones were seeded at $50 \times$ $10^{3}$ cells/well in $180 \mu \mathrm{l}$ RPMI 1640 8\% HS containing 150 IU IL-2. The treatments were carried out $24 \mathrm{~h}$ after seeding by adding decitabine at $500 \mathrm{nM}$ for $72 \mathrm{~h}$; then, HDACi treatments were performed for additional $48 \mathrm{~h}$.

For flow cytometry experiments, lymphocytes were seeded at $4 \times 10^{5}$ cells/well in a flat-bottomed 96 -well plate 
in $180 \mu \mathrm{l}$ RPMI 1640 8\% HS. Cells were treated with different HDACi for $48 \mathrm{~h}$.

For tumor cell culture, $10^{5}$ cells were seeded per well of 6-well plate in $2 \mathrm{ml}$ of culture medium and then incubated at $37^{\circ} \mathrm{C}$ for $24 \mathrm{~h}$. Cells were then treated with a combination of $0.5 \mu \mathrm{M}$ decitabine for $72 \mathrm{~h}$ followed by HDACi, VPA $5 \mathrm{mM}$, SAHA $2.5 \mu \mathrm{M}$, ODB $7.5 \mu \mathrm{M}$, NODB $2.5 \mu \mathrm{M}$, ODH $2.5 \mu \mathrm{M}$, and NODH $25 \mathrm{nM}$ for $48 \mathrm{~h}$.

\section{Cell viability test}

After treatments, cell viability was measured using CellTiter-Glo kit (Promega) according to the manufacturer's protocol.

\section{Flow cytometry analysis}

The day of analysis, cells were stained in a conical-bottomed 96-well plate at $10^{5}$ cells/well. The plate was centrifuged at $800 \times g$ for $1 \mathrm{~min}$, and the pellets were washed using $200 \mu \mathrm{l} /$ well of PBS containing BSA 0.1\% (wash buffer). Antibodies (see Additional file 2: Table S2) were used at a dilution of $1 / 30$ in the wash buffer, and then, the plate was incubated at $4{ }^{\circ} \mathrm{C}$ for $30 \mathrm{~min}$. Later, two washings were performed using the wash buffer prior to flow cytometry analysis. All flow cytometry data were acquired with FACScalibur (BD biosciences) using the CellQuest software (BD Biosciences) and analyzed by FlowJo software.

\section{Real-time RT-PCR}

Expression levels of the gene of interest were analyzed using real-time PCR. Reverse transcription was performed with the M-MLV Reverse Transcriptase (Invitrogen) using aliquots of total RNA extracted from MPM cells NucleoSpin $^{\circ}$ RNA kits. All real-time PCR reactions were performed using the Mx3005P QPCR Systems (Stratagen Products, Agilent Technologies), and the amplifications were done using the SYBR Green PCR Master Mix SAB bioscience (Qiagen) mixed with Oligonucleotides QuantiTect Primer (Qiagen). The thermal cycling conditions were composed of 1 cycle at $95^{\circ} \mathrm{C}$ for $10 \mathrm{~min}, 40$ cycles at $95^{\circ} \mathrm{C}$ for $30 \mathrm{~s}$ and $60^{\circ} \mathrm{C}$ for $1 \mathrm{~min}$, and 1 cycle at $95^{\circ} \mathrm{C}$ for
$1 \mathrm{~min}, 60^{\circ} \mathrm{C}$ for $30 \mathrm{~s}$, and $95^{\circ} \mathrm{C}$ for $30 \mathrm{~s}$. The experiments were carried out in duplicate for each data point. All the qPCR data were analyzed by MxPro software.

Measurement of NY-ESO-1-specific CD8+ T-cells activation MPM cells were treated or not with decitabine $72 \mathrm{~h} /$ HDACi $48 \mathrm{~h}$ prior to be seeded at $10^{5}$ cells/well and then co-cultured with NY-ESO-1-specific CD8+ T-cells [19] at $5 \times 10^{4}$ cells/well in complete RPMI 1640 medium containing $10 \mathrm{mg} \mathrm{mL} \mathrm{m}^{-1}$ of brefeldin A (Sigma-Aldrich) for $6 \mathrm{~h}$ at $37{ }^{\circ} \mathrm{C}$, then washed. Cells were stained with $\mathrm{APC}$-conjugated mouse anti-human CD8 at $1 / 30$ for $30 \mathrm{~min}$ at $4{ }^{\circ} \mathrm{C}$ in wash buffer, and PE-conjugated mouse anti-human IFN- $\gamma$ monoclonal antibodies at $1 / 50$ for $30 \mathrm{~min}$ at room temperature in permeabilization buffer. CD8 and IFN- $\gamma$ expression were analyzed using flow cytometry.

\section{Statistical analysis}

Data presented are means \pm S.E.M. The unpaired $t$ test and one-way ANOVA test followed by Holm-Sidak's multiple comparisons test were used to measure the statistical differences. Statistical analyses were performed using GraphPad Prism 6 (GraphPad Software Inc., San Diego, CA, USA). A $P$ value of 0.05 or less was considered as significant.

\section{Results}

Effect of histone deacetylase inhibitors (HDACi) on lymphocyte viability

The first step in this study was to test the toxicity of the novel compounds, in comparison with the two HDACi already known and used clinically (VPA and SAHA), on lymphocytes and on activated CD8 $\mathrm{T}$ lymphocytes clones. For this, we performed a cell viability assay after $48 \mathrm{~h}$ of treatment with increasing doses of HDACi on cells pretreated or not with decitabine. The $\mathrm{IC}_{50}$ were determined and summarized in Table 1, and the area under the curve (AUC) are provided as Additional file 3: Table S3.

Table 1 HDACi IC 50 on immune cells

\begin{tabular}{|c|c|c|c|c|}
\hline & \multicolumn{2}{|l|}{ Lymphocytes } & \multicolumn{2}{|l|}{ T-CD8 clones } \\
\hline & - Decitabine & + Decitabine $500 \mathrm{nM}$ & - Decitabine & + Decitabine $500 \mathrm{nM}$ \\
\hline VPA & $6.75 \pm 0.06 \mathrm{mM}$ & $3.05 \pm 0.11 \mathrm{mM}$ & $3.80 \pm 0.06 \mathrm{mM}$ & $0.02 \pm 0.10 \mathrm{mM}$ \\
\hline SAHA & $13.66 \pm 0.05 \mu \mathrm{M}$ & $9.9 \pm 0.08 \mu \mathrm{M}$ & $1.29 \pm 0.05 \mu \mathrm{M}$ & $0.08 \pm 0.06 \mu \mathrm{M}$ \\
\hline ODB & ND & ND & $28.81 \pm 0.05 \mu \mathrm{M}$ & $0.17 \pm 0.12 \mu \mathrm{M}$ \\
\hline NODB & $46.01 \pm 0.06 \mu \mathrm{M}$ & $26.22 \pm 0.05 \mu \mathrm{M}$ & $17.99 \pm 0.05 \mu \mathrm{M}$ & $0.37 \pm 0.12 \mu \mathrm{M}$ \\
\hline $\mathrm{ODH}$ & $9.62 \pm 0.05 \mu \mathrm{M}$ & $5.28 \pm 0.09 \mu \mathrm{M}$ & $1.86 \pm 0.05 \mu \mathrm{M}$ & $0.07 \pm 0.07 \mu \mathrm{M}$ \\
\hline $\mathrm{NODH}$ & $0.43 \pm 0.06 \mu \mathrm{M}$ & $0.19 \pm 0.11 \mu \mathrm{M}$ & $0.03 \pm 0.05 \mu \mathrm{M}$ & $0.002 \pm 0.06 \mu \mathrm{M}$ \\
\hline
\end{tabular}

$\mathrm{IC}_{50}$ values were determined using GraphPad prism, Prism 6 for Windows, by curve fitting using a sigmoidal dose response model. Results are the means \pm S.E.M of three independent experiments 
In Fig. 1, we can observe that the chemotherapeutic agents were toxic for lymphocytes and CD8+ T-lymphocyte clones at concentrations depending on compounds. For all tested molecules, $\mathrm{IC}_{50}$ were lower on CD8+ T-lymphocyte clones compared to total lymphocytes and are coherent with those we previously obtained on cancer cells [16]. Combination with decitabine did not increase drastically the toxicity of HDACi towards total lymphocytes (Fig. 1, Table 1, and Additional file 3: Table S3). However, on $\mathrm{CD} 8 \mathrm{~T}$-cell clones, $\mathrm{IC}_{50}$ of $\mathrm{HDACi}$ were strongly decreased in the presence of decitabine (Fig. 1, Table 1, and Additional file 3: Table S3). With lymphocytes, we note that some cells persist despite being treated with the highest concentration of compounds. Indeed, in the presence or not of decitabine, approximately $40 \%$ of the cells survived with $5 \mathrm{mM}$ of VPA and with the highest doses of SAHA, ODH, and
$\mathrm{NODH}$, and about $50-60 \%$ of the cells survived with the highest dose of ODB and NODB.

\section{Histone deacetylase inhibitors effect on immune cells subpopulations}

The aim of our strategy is to induce an anti-tumor immune response to cure malignant pleural mesothelioma by using combinations of epigenetic drugs including HDACi. Therefore, it was necessary to study the effect of these HDACi on sub-populations of lymphocytes implicated in this immune response. Doses of compounds were chosen according to blood concentrations of VPA and SAHA measured during clinical trials [20-23] and to induce approximately $50 \%$ of decrease of cell viability for ODB, NODB, ODH, and NODH on total lymphocytes (Fig. 1). Toxicity of the compounds was tested on natural killer cells (NK) (CD56+, CD16+), on regulatory

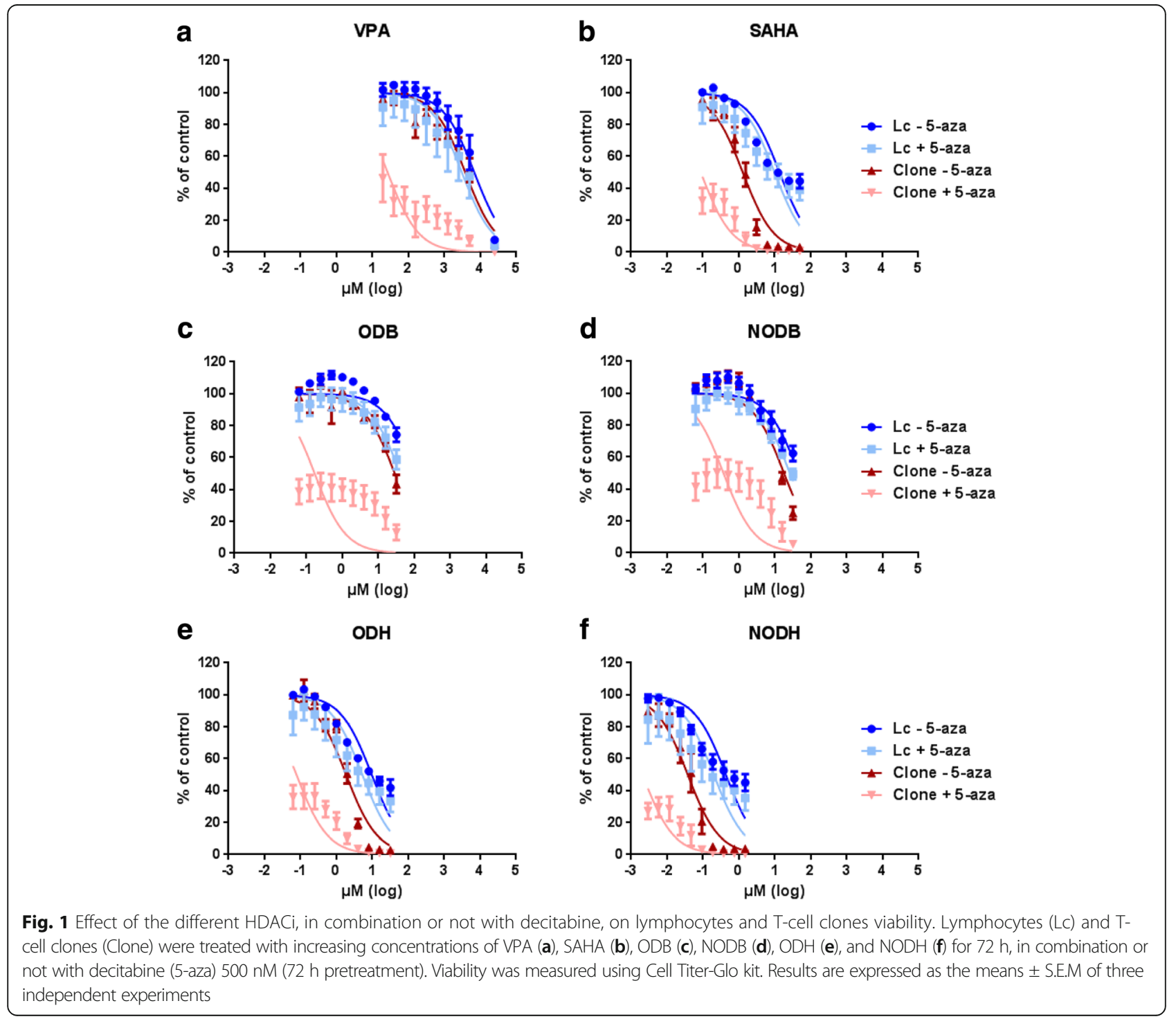


T-cells (Treg) (CD4+, CD25+, CD127 low and Foxp3+), on CD4 and CD8 naïve T-cells (CD4+, CCR7+ and CD45RA+, and CD8+, CCR7+ and CD45RA+, respectively), and on CD4 and CD8 memory T cells (CD4+ and $\mathrm{CD} 45 \mathrm{RO}+$, and $\mathrm{CD} 8+$ and $\mathrm{CD} 45 \mathrm{RO}+$, respectively).

The proportion of NK cells was decreased by almost all HDACi and more particularly by ODH and VPA (more than $50 \%$ in comparison to the untreated lymphocytes) (Fig. 2a, b). Then, we analyzed the effect of the molecules on Treg cells, a subset of $\mathrm{T}$ lymphocytes implicated in the inhibition of the immune response. Figure 2c, d shows that VPA and ODH decreased Treg by approximately $95 \%$, while the other compounds reduced the proportion of this sub-population by 85 to $70 \%$ approximately. The populations of naïve and memory T-cells were not significantly affected by the different HDACi (Additional file 4: Figure S1).
Effect of HDACi in combination with decitabine on cancer testis antigens expression in mesothelioma cells

Cancer testis antigens (CTA) are a category of tumor antigens that are highly restricted to tumors. Their expression is associated with spontaneous antitumor immune response, and their discovery has led to the development of immunotherapy strategies and to antigen-specific cancer vaccines [24]. It was demonstrated that CTA expression can be induced using combination of decitabine/ HDAC inhibitor. We and others previously demonstrated that CTA can be induced in mesothelioma cells using this strategy $[12,13]$. Here, we aimed at evaluating the immunogenicity of the new HDACi in combination with decitabine. For this work, we used the mesothelioma cell lines Meso96, Meso34, and Meso45, established and characterized in the laboratory [18]. These treatments were poorly toxic on Meso96 and Meso34
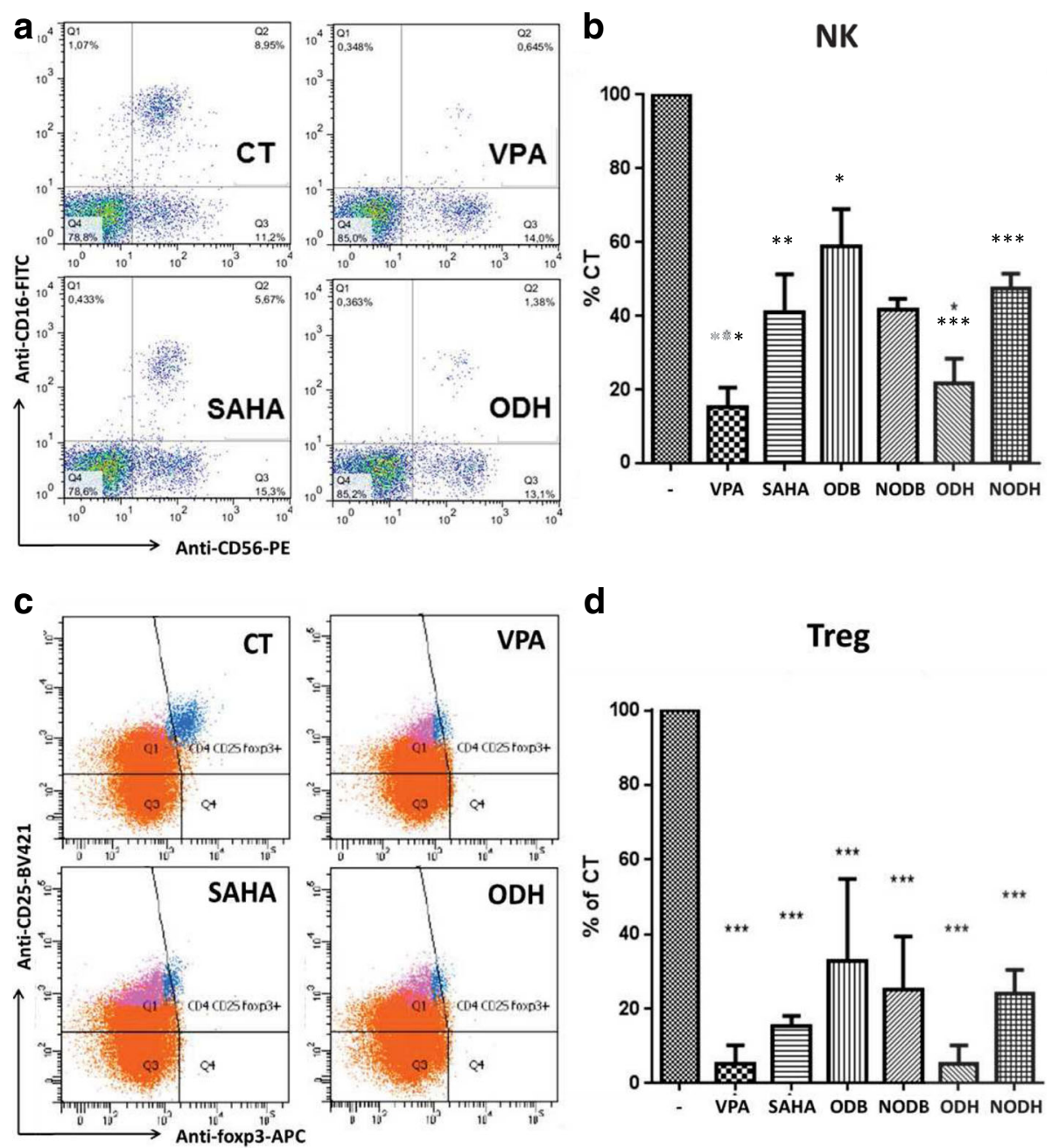

Fig. 2 Effect of HDAC inhibitors on NK and Treg cells. Lymphocytes obtained by elutriation were treated with HDACi at the following concentrations for $48 \mathrm{~h}$ : VPA $5 \mathrm{mM}$, SAHA $1 \mu \mathrm{M}$, ODB $32 \mu \mathrm{M}, \mathrm{NODB} 8 \mu \mathrm{M}, \mathrm{ODH} 4 \mu \mathrm{M}$, and NODH $50 \mathrm{nM}$. a and $\mathbf{c}$ are examples of results obtained on natural killer cells (NK) and regulatory T cells (Treg) using flow cytometry. $\mathbf{b}$ and $\mathbf{d}$ are graphic representations of HDACi effect on NK and Treg proportions (respectively). Results are expressed as the means \pm S.E.M of three independent experiments. ${ }^{*} p<0.05,{ }^{* *} p<0.01$ and ${ }^{* *} p<0.001$ 
(Additional file 5: Figure S2). However, on Meso45, molecules used alone induced from 10 to $60 \%$ of decrease of cell viability. With HDACi in combination with decitabine, the decrease of cell viability was from 60 to $90 \%$ (Additional file 5: Figure S2). Figure 3a, b shows the effect of the new compounds in combination with decitabine on the mRNA expression of the CTA, NY-ESO-1 (Fig. 3a), and the recognition of the treated cells by a CD8 T-cell clone specific of this antigen (Fig. 3b). HDACi alone have no effect on CTA expression
(Additional file 6: Figure S3). All HDACi increased significantly the mRNA expression of NY-ESO-1 induced by decitabine. This effect was associated with recognition of the treated mesothelioma cells by the HLA-A $0201 / N Y-E S O-1(157-165)$-specific CD8 T-cell clone, characterized by the production of IFN- $\gamma$ after co-culture experiments. This result was not associated with an increase of HLA molecules at mesothelioma cell surface which demonstrated that recognition by T-cell clone was driven by the increase of NY-ESO-1
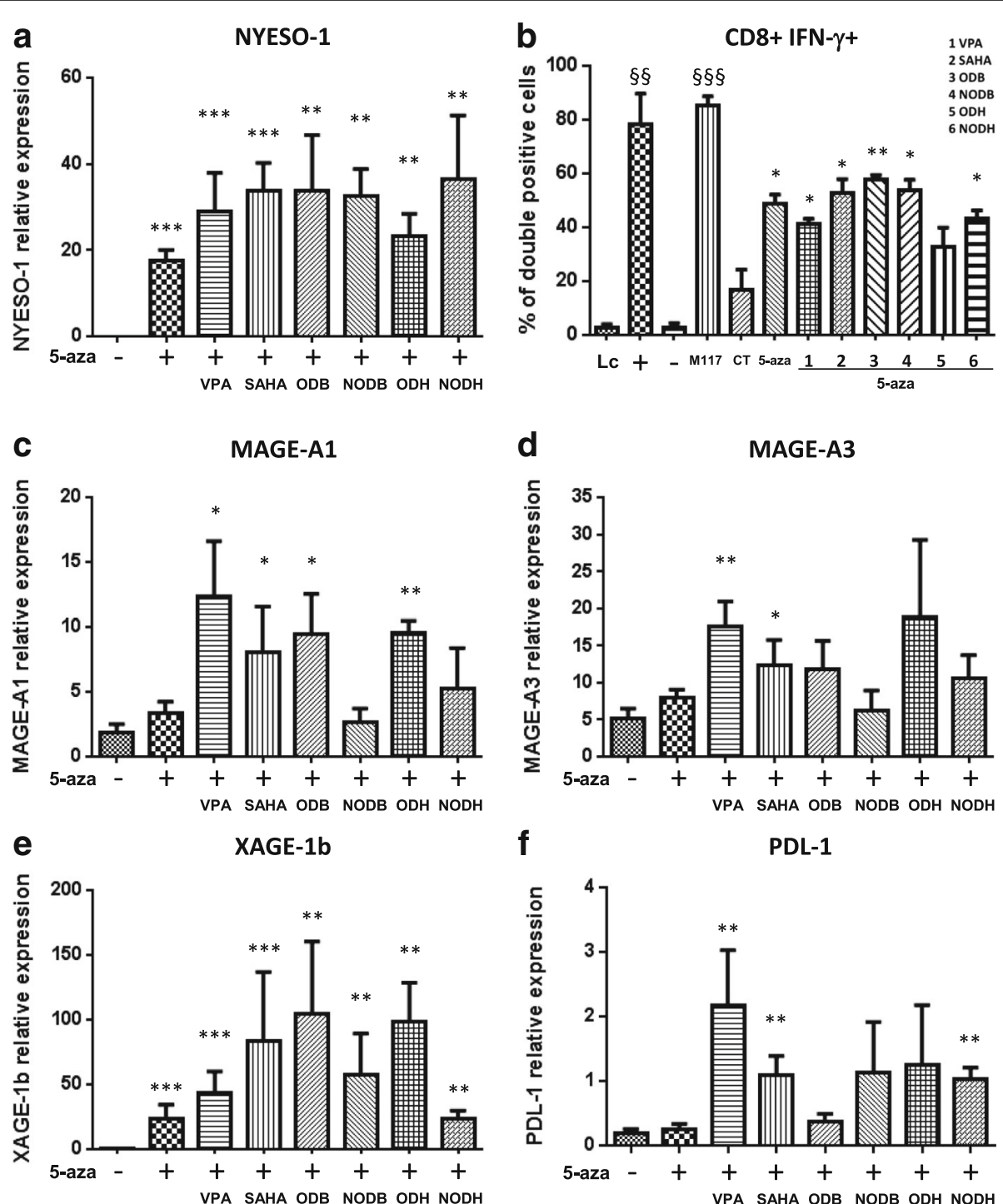

f

PDL-1

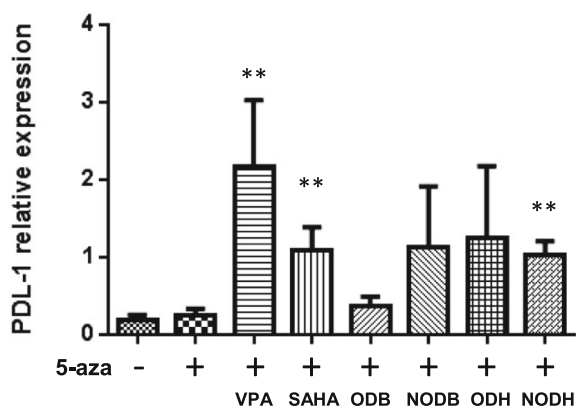

Fig. 3 HDACi increase decitabine-induced CTA expression in Meso96 cells and allow tumor cell recognition by CD8+ NY-ESO-1 T-cell clone. Meso96 cells were treated with: VPA 5 mM, SAHA $2.5 \mu \mathrm{M}$, ODB $7.5 \mu \mathrm{M}$, NODB $2.5 \mu \mathrm{M}, \mathrm{ODH} 2.5 \mu \mathrm{M}$, and NODH $25 \mathrm{nM}$ (48 h) in combination or not with decitabine (5-aza) $500 \mathrm{nM}$ (72 h pretreatment). NY-ESO-1 (a), MAGE-A1 (c), MAGE-A3 (d), XAGE-1b (e), and PD-L1 (f) mRNA were measured using real time PCR. ${ }^{*} p<0.05,{ }^{* *} p<0.01$ and ${ }^{* *} p<0.001$. b Interferon (IFN- $\gamma$ ) production by NY-ESO-1-specific CD8+ T-cell clone in response to Meso96 treated or not with the combination decitabine $+/-$ HDACi. IFN- $\gamma$ production was measured by intracytoplasmic staining of IFN- $\gamma$ and surface staining of CD8, followed by flow cytometry analysis. LC: lymphocytes alone, +: NY-ESO-1 (157-165) peptide (10 $\mu$ M), -: MUC1 (950-958) peptide $(10 \mu \mathrm{M})$, M117: melanoma cell line that expresses NY-ESO-1, CT: untreated Meso96 cells. Results are expressed as the means \pm S.E.M of three independent experiments. $\S$ vs $L C,{ }^{\S \S} p<0.001,{ }^{\S \S \S} p<0.001$; ${ }^{*}$ vs $C T,{ }^{*} p<0.05$ and ${ }^{* *} p<0.01$ 
expression (Additional file 7: Figure S4). We extended this study to the mRNA expression of other CTA, MAGE-A1 (Fig. 3c), MAGE-A3 (Fig. 3d) and XAGE-1b (Fig. 3e). Globally, all HDACi increased CTA induced by decitabine. However, some differences can be observed depending on the CTA and on the molecule evaluated. Similar results were obtained using two additional MPM cell lines, Meso34 and Meso45 (Additional file 8: Figure S5 and Additional file 9: Figure S6). We also assessed the effect of these HDAC inhibitors on the mRNA expression of PD-L1 (B7-H1), an immunomodulatory molecule that inhibits $\mathrm{T}$ cell-mediated immune response [25]. Whereas decitabine alone did not affect the mRNA expression of PD-L1, when combined with VPA, SAHA, or NODH, a significant increase of PD-L1 mRNA was observed (Fig. 3f). In the two additional MPM cell lines, decitabine, some HDACi alone, VPA, SAHA and ODH in particular, and all the combinations increased PD-L1 expression (Additional file 8: Figure S5 and Additional file 9: Figure S6).

\section{Effect of decitabine alone and/or in combination with HDACi on RIG-1 and MDA5 mRNA expression in mesothelioma cells}

Several works demonstrated that decitabine can induce interferon-responsive genes such as melanoma differentiation-associated antigen-5 (MDA5) and retinoic acid-inducible gene I (RIG-1) in different cancer cell lines $[7,10,11,26]$. The induction of this pathway can lead to cell cycle arrest. In MPM cells, the treatment with decitabine alone increased significantly the expression of both RIG-1 and MDA5 mRNA expression in Meso34 (Fig. 4c, d) and Meso45 (Fig. 4e, f) but not in Meso96 (Fig. 4a, b). HDACi alone induced no modifications of RIG-1 and MDA5 expression in all tested cell lines (Additional file 10: Figure S7). Decitabine in combination with HDACi had negligible effect on RIG-1 and MDA5 expression in Meso96 (Fig. 4a, b); however, RIG-1 and MDA5 expression induced by decitabine was reduced in Meso34 (Fig. 4c, d) and Meso45 (Fig. 4e, f).

\section{Discussion}

Malignant pleural mesothelioma (MPM) is a locally invasive and rapidly fatal malignancy often diagnosed $30-40$ years after exposure to asbestos. To date, there is no effective therapeutic strategy against this disease; therefore, the development of new treatment is required. The use of epigenetic drugs represents a promising approach to treat people suffering from MPM. The hypomethylating drug decitabine (5-azaCdR) and HDAC inhibitors have many positive effects either by promoting growth arrest, apoptosis or differentiation of tumor cells $[27,28]$. In a previous work on a mice model of mesothelioma, we have shown that the use of these drugs alone did not have a strong anti-tumoral effect, while the use of the combination of decitabine/HDAC inhibitors, VPA or SAHA, was efficient [12]. The use of these FDA-approved drugs had an impact on the expression of CTA in mesothelioma cells and induced an anti-tumor immune response in vivo. However, these compounds have many toxic properties, notably hematologic toxicity, which requires the development of new HDAC inhibitors that are less toxic to healthy cells, act at low doses and preserve immune cells.

In this study, we aimed at characterizing the toxicity of new HDACi, in comparison with VPA and SAHA, on immune cells. Then, we studied their immunogenicity, in combination with decitabine, on MPM cells by measuring the mRNA expression of CTA, PD-L1, MDA5, and RIG-1. Our results showed that toxicity on immune cells and immunogenicity on MPM cells of the tested molecules are different. This study demonstrates that a careful evaluation of HDACi is required to define the best combination strategy for immunotherapy application.

All the tested molecules were toxic for immune cells. However, whereas high doses of HDACi led to the death of $100 \%$ of CD8 T-cells clones on total lymphocytes, maximal toxicity depended on the molecule used. When compared to blood concentrations reach in clinic for SAHA, approximately $1 \mu \mathrm{M}[22,23]$, these results are coherent with the hematological toxicity observed in patients. Concerning VPA, blood concentrations observed during treatments are around $1 \mathrm{mM}[20,21]$. At this concentration, VPA presents weak hematological toxicity according to our observation. Extrapolated to our new compounds, NODH seems to be the more promising. Indeed, this HDACi is 100 times more active to induce histone $\mathrm{H3}$ acetylation in cells than SAHA [29]. Whereas SAHA is toxic for both lymphocytes and CD8 T-cells at clinical doses measured in blood from patients (approximately 1 to $4 \mu \mathrm{M}$ ) [30,31], NODH at 10 to $40 \mathrm{nM}, 100$ times lower concentrations than SAHA, was poorly toxic.

Additional analyses demonstrated that Treg and NK cell populations were particularly affected by HDACi. All the tested compounds reduced significantly the proportion of Treg. However, VPA and ODH compounds were the most active drugs on these cells. Epigenetic mechanisms could be responsible for these effects. There is no evidence of a regulation of Treg and NK cell markers through modulation of histone acetylation. FoxP3, a strong marker of Treg, is well-known to be regulated by methylation [32], and recent study suggests that CD16 expression could also be regulated by methylation [33]. Decitabine alone reduced moderately Treg and NK proportion (Additional file 11: Figure S8). However, here, it is difficult to determine whether the effect was more a toxicity or an epigenetic regulation of cell 

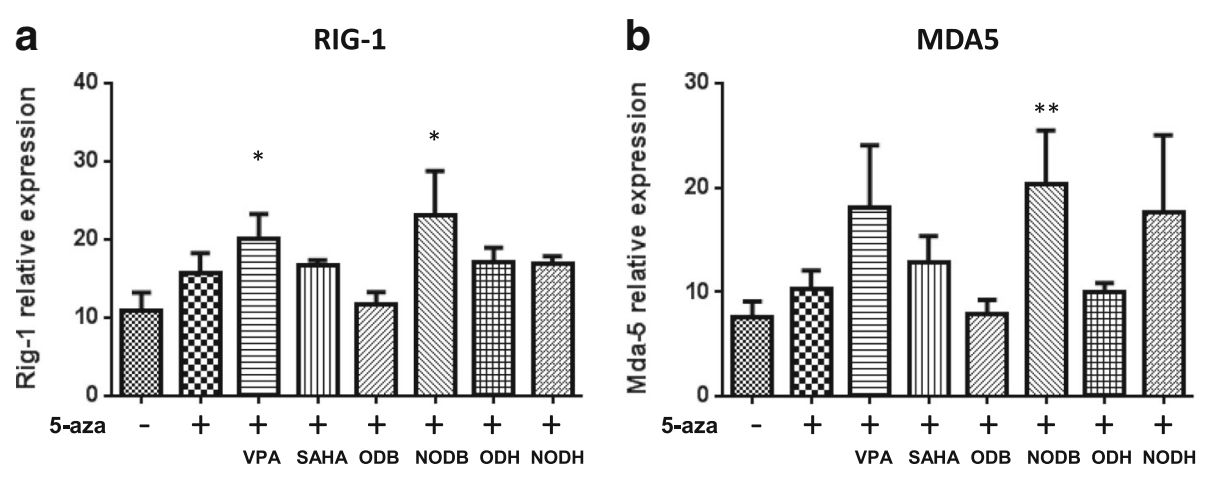

C

RIG-1

MDA5

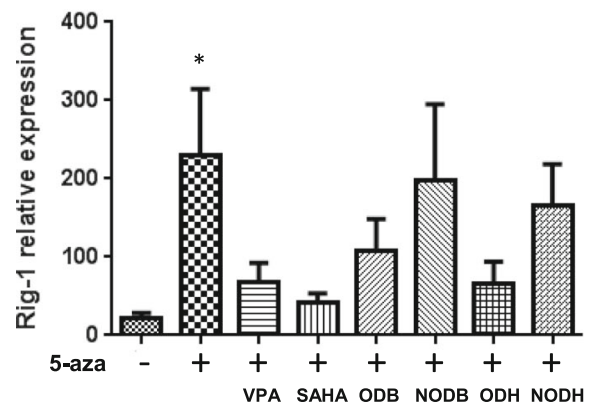

d

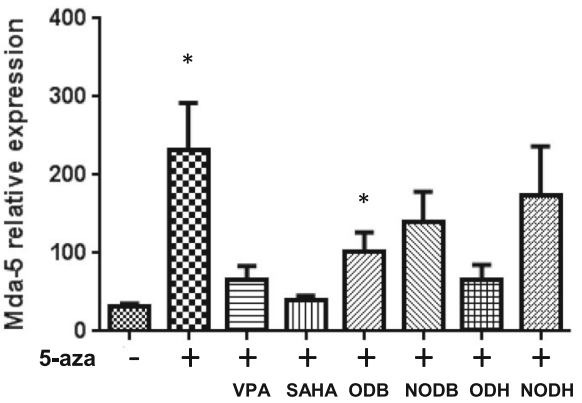

e

RIG-1

f

MDA5
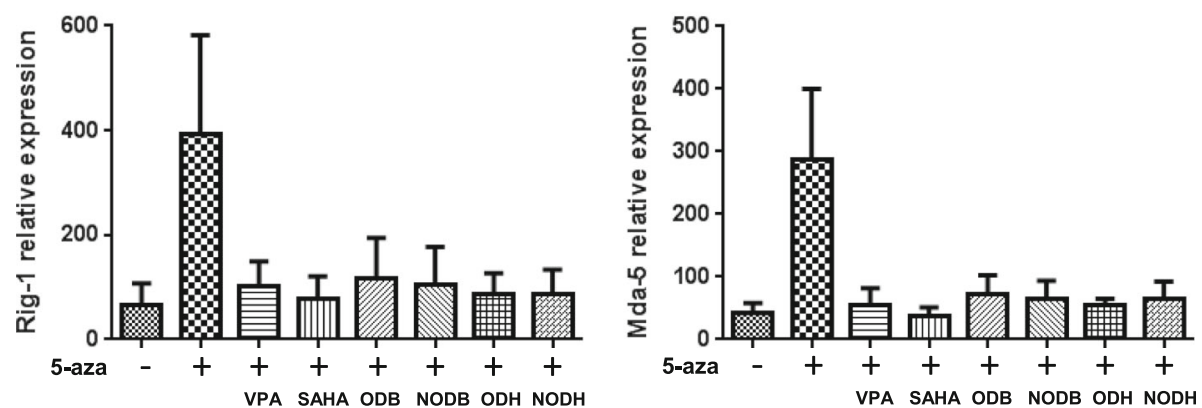

Fig. 4 HDACi modulate decitabine-induced RIG-1 and MDA5 expression in MPM cells. Meso96 (a, b), Meso34 (c, d), and Meso45 (e, f) cells were treated with: VPA 5 mM, SAHA $2.5 \mu \mathrm{M}, \mathrm{ODB} 7.5 \mu \mathrm{M}$, NODB $2.5 \mu \mathrm{M}, \mathrm{ODH} 2.5 \mu \mathrm{M}$, and NODH $25 \mathrm{nM}(48 \mathrm{~h}$ ) in combination or not with decitabine (5-aza) $500 \mathrm{nM}$ (72 h pretreatment). RIG-1 (a, $\mathbf{c}$, and $\mathbf{e}$ ) and MDA5 (b, d, and $\mathbf{f}$ ) mRNA expression were measured using real time PCR. ${ }^{*} p<0.05$ and ${ }^{* *} p<0.01$

markers. A mechanistic study is necessary to identify mechanisms involved.

In clinic, the effect of HDACi on Treg cell population is not clear. Some studies mentioned a decrease of Treg cell population following HDACi treatment $[34,35]$ whereas others reported an increase of Treg number and function [36]. In vitro and preclinical models suggest that reduction of Treg cells by HDACi depends on the specificity and on the dose of the molecules used [37]. According to the implication of Treg cells in the inhibition of anti-tumor immune response, this effect of HDACi could be beneficial for immunotherapy strategy. NK cells are implicated in innate immunity. HDACi were already described as toxic for these particular cells [38-40], as observed in our study. This action of HDACi could be deleterious for induction of anti-tumor response in vivo regarding the implication of NK cells in tumor immune-surveillance [41, 42] and metastasis control [43]. However, on the contrary of Treg cells, the impact of HDACi on NK cell proportion is more moderate. Indeed, Treg cells were reduced from 65 to $95 \%$ and NK cells were reduced from 40 to $85 \%$.

Several studies have demonstrated the immunogenicity of the combination decitabine/HDACi on cancer cells, notably on mesothelioma cells $[12,13]$. In this study, we showed that all HDACi tested increased decitabine-induced CTA expression which was associated with an increase activation of a NY-ESO-1-specific CD8 T cell in vitro. This result was not associated with an increase of HLA molecules at mesothelioma cell surface (Additional file 7: Figure S4) which demonstrated that the recognition by $\mathrm{T}$ cell clone was driven by the increase of NY-ESO-1 expression. We previously demonstrated that HDAC1 is in part responsible for 
NY-ESO-1 repression [44]. Thus, an action of all tested HDACi on decitabine-induced NY-ESO-1 expression was expected according to their inhibitory activity on HDAC1 (Additional file 12: Figure S9). For the other CTA tested, there is no available information on the HDAC implicated in their regulation. Additionally, we observed that decitabine increased RIG-1 and MDA5 expression in Meso34 and Meso45 whereas in Meso96 the modifications observed were negligible. This observation is novel in the field of MPM. RIG-1 and MDA5 are two receptors implicated in interferon signaling pathway and viral infection response. The increase of RIG- 1 and MDA 5 expression by decitabine was described as the consequence of the induction of endogenous virus replication and then of the activation of the interferon signaling pathway $[10,11]$. In Meso34 and Meso45, combination with HDACi reduced induction of RIG-1 and MDA5 expression by decitabine. Anti-replicative effect of HDACi on viruses was already described [45] which could explain the results obtained. Thus, immunogenicity of decitabine could be reduced. However, induction of endogenous viruses by decitabine could also be responsible for an increase of the mutation rate in MPM cells and then to an improve adaptability to their environment. Regarding our previous results obtained in vivo with the combination decitabine/HDACi [12], it seems that inhibition of interferon signaling pathway induced by decitabine is not determinant for the induction of an anti-tumor response. Moreover, recent data from our laboratory has demonstrated that approximately $70 \%$ of MPM have a non-functional interferon pathway (Achard et al., Oncotarget, 2015).

Recently, immune check point inhibitors were identified as responsible for inhibition of anti-tumor immune response and then appear as promising therapeutic targets [17]. The PD-1/PD-L1 axis is of particular interest regarding the impressive results observed in clinic with anti-PD-1 blocking antibody. Therefore, the impact of treatments on PD-L1 expression in cancer cells needs to be monitored to avoid a fail of the strategy evaluated. Indeed, several studies demonstrated that the expression of PD-L1 can be increased in cancer cells following HDACi or hypomethylating agent treatment [46]. In MPM cells, we observed that PD-L1 was induced by the combination decitabine/HADCi. This observation suggests that epigenetic regulation of CTA expression and PD-L1 could be associated.

In view of our results, it seems that there is no really more appropriate molecule when regarding immunogenicity. Our study suggests that the combination decitabine/ HDACi should be associated with anti-PD-L1 strategy given that all combinations induced PD-L1 gene expression. However, NODH could be interesting regarding its pharmacological properties. Indeed, this HDACi is active at nanomolar concentrations and at concentrations which induce gene expression, $\mathrm{NODH}$ is moderately toxic for lymphocytes when combined with decitabine ( $25 \%$ of cell death). Unfortunately, toxicity on T-cell clone should be considered in the protocol of treatment to avoid hampering an ongoing anti-tumor immune response.

\section{Conclusions}

From our work, it seems that more careful studies are needed on the intrinsic properties of HDACi on both immune and cancer cells. Indeed, data obtained will be useful to define the most appropriate combination of molecules for immunotherapy strategies. Likewise, a better comprehension of molecular players participating in the regulation of genes implicated in immunogenicity is required to design optimized HDACi. To date, anti-PD-1/ PD-L1 strategy needs to be considered in combination with decitabine and HDACi for MPM treatment in order to overcome a possible induction of PD-L1 expression.

\section{Additional files}

Additional file 1: Table S1. Structure and class of the compounds used in this study. (DOCX $37 \mathrm{~kb})$

Additional file 2: Table S2. Detailed information about the antibodies used in the experiments. (DOCX $16 \mathrm{~kb}$ )

Additional file 3: Table S3. HDACi AUC on immune cells. (DOCX 14 kb) Additional file 4: Figure S1. Effect of HDAC inhibitors on naïve and memory T-cells. Lymphocytes obtained by elutriation were treated with HDACi at the following concentrations for $48 \mathrm{~h}$ : VPA $5 \mathrm{mM}$, SAHA $1 \mu \mathrm{M}$, ODB $32 \mu \mathrm{M}, \mathrm{NODB} 8 \mu \mathrm{M}, \mathrm{ODH} 4 \mu \mathrm{M}$, and NODH $50 \mathrm{nM}$. Graphics represent the effect of the compounds on CD4 (a) and CD8 (b) naive Tcells and on CD4 (c) and CD8 (d) memory T-cells. Results are expressed as the means \pm S.E.M of three independent experiments. (PDF $108 \mathrm{~kb}$ )

Additional file 5: Figure S2. Effect of decitabine and $\mathrm{HDACi}$, in combination or not, on MPM cell growth. MPM cells were treated with: VPA 5 mM, SAHA $2.5 \mu \mathrm{M}$, ODB $7.5 \mu \mathrm{M}$, NODB $2.5 \mu \mathrm{M}, \mathrm{ODH} 2.5 \mu \mathrm{M}$, and $\mathrm{NODH} 25 \mathrm{nM}(48 \mathrm{~h})$ in combination or not with decitabine (5-aza) $500 \mathrm{nM}$ (72 h pretreatment). Viability was measured using Cell Titer Glo kit (Promega). ${ }^{*} p<0.05,{ }^{* *} p<0.01$ and ${ }^{* *} p<0.001$. (PDF $179 \mathrm{~kb}$ )

Additional file 6: Figure S3. HDACi increase decitabine-induced CTA expression in Meso96 cells. Meso96 cells were treated with: VPA 5 mM, SAHA $2.5 \mu \mathrm{M}$, ODB $7.5 \mu \mathrm{M}$, NODB $2.5 \mu \mathrm{M}, \mathrm{ODH} 2.5 \mu \mathrm{M}$, and NODH $25 \mathrm{nM}$ $(48 \mathrm{~h})$ in combination or not with decitabine (5-aza) $500 \mathrm{nM}(72 \mathrm{~h}$ pretreatment). NY-ESO-1, MAGE-A1, MAGE-A3, XAGE-1b and PD-L1 mRNA were measured using real time PCR. (PDF $199 \mathrm{~kb}$ )

Additional file 7: Figure S4. Expression of HLA ABC in Meso96 treated with decitabine/HDACi combinations. Meso96 were treated with: VPA $5 \mathrm{mM}$, SAHA $2.5 \mu \mathrm{M}$, ODB $7.5 \mu \mathrm{M}$, NODB $2.5 \mu \mathrm{M}, \mathrm{ODH} 2.5 \mu \mathrm{M}$, and $\mathrm{NODH}$ $25 \mathrm{nM}(48 \mathrm{~h})$ in combination or not with decitabine (5-aza) $500 \mathrm{nM}$ (72 h pretreatment). Then, $\mathrm{HLA} A B C$ expression was measured using flow cytometry. Results are expressed as the means \pm S.E.M of three independent experiments. (PDF $91 \mathrm{~kb}$ )

Additional file 8: Figure S5. HDACi increase decitabine-induced CTA expression in Meso34 cells. Meso34 cells were treated with: VPA 5 mM, SAHA $2.5 \mu \mathrm{M}$, ODB $7.5 \mu \mathrm{M}$, NODB $2.5 \mu \mathrm{M}, \mathrm{ODH} 2.5 \mu \mathrm{M}$, and NODH $25 \mathrm{nM}$ (48 h) in combination or not with decitabine (5-aza) $500 \mathrm{nM}$ (72 h pretreatment). NY-ESO-1, MAGE-A1, MAGE-A3, XAGE-1b and PD-L1 mRNA were measured using real time PCR. (PDF $197 \mathrm{~kb}$ )

Additional file 9: Figure S6. HDACi increase decitabine-induced CTA expression in Meso45 cells. Meso45 cells were treated with: VPA 5 mM, SAHA $2.5 \mu \mathrm{M}$, ODB $7.5 \mu \mathrm{M}$, NODB $2.5 \mu \mathrm{M}, \mathrm{ODH} 2.5 \mu \mathrm{M}$, and NODH $25 \mathrm{nM}$ (48 h) in combination or not with decitabine (5-aza) $500 \mathrm{nM}(72 \mathrm{~h}$ pretreatment). NY-ESO-1, MAGE-A1, MAGE-A3, XAGE-1b and PD-L1 mRNA were measured using real time PCR. (PDF 197 kb) 
Additional file 10: Figure S7. HDACi modulate decitabine-induced RIG1 and MDA5 expression in MPM cells. Meso34 (top), Meso45 (middle) and Meso96 (down) cells were treated with: VPA 5 mM, SAHA $2.5 \mu \mathrm{M}$, ODB $7.5 \mu \mathrm{M}, \mathrm{NODB} 2.5 \mu \mathrm{M}, \mathrm{ODH} 2.5 \mu \mathrm{M}$, and NODH $25 \mathrm{nM}(48 \mathrm{~h}$ ) in combination or not with decitabine (5-aza) $500 \mathrm{nM}$ (72 h pretreatment). RIG-1 (left) and MDA-5 (right) mRNA expression were measured using real time PCR. ${ }^{*} p<0.05,{ }^{* *} p<0.01$ and ${ }^{* * *} p<0.001$. (PDF $209 \mathrm{~kb}$ )

Additional file 11: Figure S8. Effect of decitabine on Treg and NK cells. Lymphocytes obtained by elutriation were treated with decitabine (5-aza) $500 \mathrm{nM}(72 \mathrm{~h})$. Figure are examples of results obtained on A) natural killer cells (NK) and B) regulatory T cells (Treg) using flow cytometry. (PDF 281 kb)

Additional file 12: Figure S9. Determination of HDAC1 inhibition properties of ODB, NODB, ODH and NODH. Recombinant HDAC1 activity in the presence of increasing doses of ODB, NODB, ODH and NODH were measured using Fluor de Lys ${ }^{\oplus}$ Drug Discovery Assays (Enzo Life Sciences). (PDF $89 \mathrm{~kb})$

\section{Abbreviations}

5-azaCdR: 5-Aza-2'-deoxycytidine; APC: Allophycocyanine; AUC: Area under the curve; BSA: Bovine serum albumin; CD4, CD8...: Cluster of differentiation 4, 8...; CT: Control; CTA: Cancer testis antigen; DNA: Deoxyribonucleic Acid; DTC Platform: 'Développement et Transfert Clinique' platform; FACS: Fluorescence Activated Cell Sorting; FITC: Fluorescence Iso Thio Cyanate; FoxP3: Forkhead box P3; HDACi: Histone deacetylase inhibitor; HLA: Human Leukocyte Antigens; HS: Human Serum; IC50: The half maximal inhibitory concentration; IFN$\gamma$ : Interferon- $\gamma$; IgG1: Immunoglobulin (antibody) G1; IL-2: Interleukin-2; MAGEA1, MAGE-A3: Melanoma antigen-encoding genes family A; MDA5: Differentiation-associated antigen-5; M-MLV: Moloney Murine Leukemia Virus; MPM: Malignant pleural mesothelioma; mRNA: Messenger Ribonucleic Acid; MUC1: Mucin 1; NK: Natural killer cells; NODB: 5-(6-Dimethylamino-2methyl-3-oxo-2,3-dihydrobenzofuran-2-yl)-4methyl-penta-2,4-dienoic acid benzamide; NODH: 5-(6-Dimethylamino-2-methyl-3-oxo-2,3-dihydro benzofuran-2-yl)-4methyl-penta-2,4-dienoic acid hydroxamide; NY-ESO-1: New York Oesophageal Squamous Cell Carcinoma 1; ODB: 4-Methyl-5-(2-methyl-3oxo-2,3-dihydro-benzofuran-2-yl)-penta-2,4-dienoic acid benzamide; ODH: 4Methyl-5-(2-methyl-3-oxo-2,3-dihydro-benzofuran-2-yl)-penta-2,4-dienoic acid hydroxamide; PBS: Phosphate-Buffered Saline; PD-1: Programmed cell death 1; PD-L1: Programmed death-ligand 1; PE: Phycorerythrine; PerCP: Peridininchlorophyll-protein Complex Conjugate; RIG-1: Retinoic acid-inducible gene I; RMFI: relative median fluorescent intensity; RNA: Ribonucleic Acid; RPLPO: Ribosomal Protein Lateral Stalk Subunit PO; RPMI 1640 medium: Roswell Park Memorial Institute 1640 medium; RT-PCR: Real Time-Polymerase Chain Reaction; S.E.M: Standard Error of the Mean; SAHA: Suberoylanilide hydroxamic acid; T-reg: Regulatory T cells; TSG: Tumor suppressor genes; VPA: Valproate; XAGE- $1 \mathrm{~b}: \mathrm{X}$ antigen family member $1 \mathrm{~b}$

\section{Acknowledgements}

The authors thank the Cytocell core facility for the flow cytometry experiments and the clinical transfer platform (ClC-biothérapies Nantes) for monocyte purification.

\section{Funding}

This work was supported by INSERM, CNRS, Région Pays de la Loire, the "Institut de recherche en santé respiratoire des Pays de la Loire", the "Ligue Contre le Cancer (committees of Morbihan, Sarthe, Vendée et Loire-Atlantique), ARSMESO44, Nantes University Hospital, and INSERM (France)/ CNRST (Morocco) agreement 2015/2016.

\section{Availability of data and materials}

The datasets used and analyzed in this study are available from the corresponding author on request.

\section{Authors' contributions}

$M G, E M$, and CB contributed to the conception and design of the study. DB and SD performed treatment of cells, mRNA extractions and analyses; DB and VD conducted immunological experiments; PB synthetized HDACi. DB, $P B$, and $C B$ wrote the manuscript. All authors read and approved the final manuscript.

\section{Ethics approval and consent to participate}

Mesothelioma cell line use in this work belongs to a bio-collection of mesothelioma samples from patients (DC-2011-1399) recognized by the French ministry of research. All recruited patients had received no prior anticancer therapy and gave signed, informed consent.

\section{Consent for publication}

Not applicable.

\section{Competing interests}

The authors declare that they have no competing interests.

\section{Publisher's Note}

Springer Nature remains neutral with regard to jurisdictional claims in published maps and institutional affiliations.

\section{Author details}

'CRCINA, INSERM, Université d'Angers, Université de Nantes, Nantes, France. ${ }^{2}$ Laboratory of Physiology and Physiopathology, Faculty of Sciences of Tetouan, Avenue de Sebta Mhannech II, 93002 Tetouan, BP, Morocco. ${ }^{3}$ Institut de Chimie des Milieux et Matériaux de Poitiers, UMR CNRS 7285, 4 rue Michel Brunet, TSA 521106, B27, 86073 Poitiers, France. ${ }^{4}$ Réseau épigénétique du Cancéropôle Grand Ouest, Nantes, France. ${ }^{5}$ CRCINA, IRS-UN, 8 Quai Moncousu, BP70721, 44007 Nantes Cedex 1, France.

Received: 29 January 2018 Accepted: 11 June 2018

Published online: 18 June 2018

\section{References}

1. Wagner JC, Sleggs CA, Marchand P. Diffuse pleural mesothelioma and asbestos exposure in the North Western Cape Province. Br J Ind Med. 1960;17:260-71.

2. Yap TA, Aerts JG, Popat S, et al. Novel insights into mesothelioma biology and implications for therapy. Nat Rev Cancer. 2017;17:475-88.

3. Pan Y, Liu G, Zhou F, Su B, Li Y. DNA methylation profiles in cancer diagnosis and therapeutics. Clin Exp Med. 2018:18:1-14.

4. Zhang X, Tang N, Rishi AK, et al. Methylation profile landscape in mesothelioma: possible implications in early detection, disease progression, and therapeutic options. Methods Mol Biol. 2015;1238:235-47.

5. Fraga MF, Ballestar E, Villar-Garea A, et al. Loss of acetylation at Lys16 and trimethylation at Lys 20 of histone $\mathrm{H} 4$ is a common hallmark of human cancer. Nat Genet. 2005;37:391-400.

6. Chi P, Allis CD, Wang GG. Covalent histone modifications-miswritten, misinterpreted and mis-erased in human cancers. Nat Rev Cancer. 2010; 10:457-69.

7. Karpf AR, Peterson PW, Rawlins JT, et al. Inhibition of DNA methyltransferase stimulates the expression of signal transducer and activator of transcription 1,2, and 3 genes in colon tumor cells. Proc Natl Acad Sci U S A. 1999;96:14007-12.

8. Sigalotti L, Coral S, Altomonte M, et al. Cancer testis antigens expression in mesothelioma: role of DNA methylation and bioimmunotherapeutic implications. Br J Cancer. 2002;86:979-82.

9. Weber J, Salgaller M, Samid D, et al. Expression of the MAGE-1 tumor antigen is up-regulated by the demethylating agent 5-aza-2'-deoxycytidine. Cancer Res. 1994:54:1766-71.

10. Li H, Chiappinelli KB, Guzzetta AA, et al. Immune regulation by low doses of the DNA methyltransferase inhibitor 5-azacitidine in common human epithelial cancers. Oncotarget. 2014;5:587-98.

11. Roulois D, Loo Yau H, Singhania R, et al. DNA-demethylating agents target colorectal cancer cells by inducing viral mimicry by endogenous transcripts. Cell. 2015;162:961-73.

12. Leclercq S, Gueugnon F, Boutin B, et al. A 5-aza-2'-deoxycytidine/valproate combination induces cytotoxic T-cell response against mesothelioma. Eur Respir J. 2011;38:1105-16.

13. Weiser TS, Guo ZS, Ohnmacht GA, et al. Sequential 5-Aza-2 deoxycytidinedepsipeptide FR901228 treatment induces apoptosis preferentially in cancer cells and facilitates their recognition by cytolytic $T$ lymphocytes specific for NY-ESO-1. J Immunother. 2001;24:151-61.

14. Martinet N, Bertrand P. Interpreting clinical assays for histone deacetylase inhibitors. Cancer Manag Res. 2011;3:117-41. 
15. Charrier C, Clarhaut J, Gesson JP, et al. Synthesis and modeling of new benzofuranone histone deacetylase inhibitors that stimulate tumor suppressor gene expression. J Med Chem. 2009;52:3112-5.

16. Gueugnon F, Cartron PF, Charrier $C$, et al. New histone deacetylase inhibitors improve cisplatin antitumor properties against thoracic cancer cells. Oncotarget. 2014;5:4504-15.

17. Adachi K, Tamada K. Immune checkpoint blockade opens an avenue of cancer immunotherapy with a potent clinical efficacy. Cancer Sci. 2015;106:945-50.

18. Gueugnon F, Leclercq S, Blanquart $C$, et al. Identification of novel markers for the diagnosis of malignant pleural mesothelioma. Am J Pathol. 2011;178:1033-42.

19. Fonteneau JF, Larsson M, Somersan S, et al. Generation of high quantities of viral and tumor-specific human CD4+ and CD8+ T-cell clones using peptide pulsed mature dendritic cells. J Immunol Methods. 2001;258:111-26.

20. Atmaca A, Al-Batran SE, Maurer A, et al. Valproic acid (VPA) in patients with refractory advanced cancer: a dose escalating phase I clinical trial. $\mathrm{Br} J$ Cancer. 2007:97:177-82.

21. Munster P, Marchion D, Bicaku E, et al. Phase I trial of histone deacetylase inhibition by valproic acid followed by the topoisomerase II inhibitor epirubicin in advanced solid tumors: a clinical and translational study. J Clin Oncol. 2007:25:1979-85.

22. Kelly WK, O'Connor OA, Krug LM, et al. Phase I study of an oral histone deacetylase inhibitor, suberoylanilide hydroxamic acid, in patients with advanced cancer. J Clin Oncol. 2005;23:3923-31.

23. Rubin EH, Agrawal NG, Friedman EJ, et al. A study to determine the effects of food and multiple dosing on the pharmacokinetics of vorinostat given orally to patients with advanced cancer. Clin Cancer Res. 2006;12:7039-45.

24. Salmaninejad A, Zamani MR, Pourvahedi M, et al. Cancer/testis antigens: expression, regulation, tumor invasion, and use in immunotherapy of cancers. Immunol Investig. 2016;45:619-40.

25. Wang $X$, Teng F, Kong $L$, et al. PD-L1 expression in human cancers and its association with clinical outcomes. Onco Targets Ther. 2016;9:5023-39.

26. Karpf AR, Lasek AW, Ririe TO, et al. Limited gene activation in tumor and normal epithelial cells treated with the DNA methyltransferase inhibitor 5aza-2'-deoxycytidine. Mol Pharmacol. 2004;65:18-27.

27. Lane AA, Chabner BA. Histone deacetylase inhibitors in cancer therapy. J Clin Oncol. 2009;27:5459-68.

28. Kristensen LS, Nielsen HM, Hansen LL. Epigenetics and cancer treatment. Eur J Pharmacol. 2009;625:131-42.

29. Blanquart C, Francois M, Charrier C, et al. Pharmacological characterization of histone deacetylase inhibitor and tumor cell-growth inhibition properties of new benzofuranone compounds. Curr Cancer Drug Targets. 2011;11:919-28.

30. Fakih MG, Pendyala L, Fetterly G, et al. A phase I, pharmacokinetic and pharmacodynamic study on vorinostat in combination with 5-fluorouracil, leucovorin, and oxaliplatin in patients with refractory colorectal cancer. Clin Cancer Res. 2009;15:3189-95.

31. Gojo I, Tan M, Fang HB, et al. Translational phase I trial of vorinostat (suberoylanilide hydroxamic acid) combined with cytarabine and etoposide in patients with relapsed, refractory, or high-risk acute myeloid leukemia. Clin Cancer Res. 2013;19:1838-51.

32. Floess S, Freyer J, Siewert C, et al. Epigenetic control of the foxp3 locus in regulatory T cells. PLoS Biol. 2007;5:e38.

33. Victor AR, Weigel C, Scoville SD, et al. Epigenetic and posttranscriptional regulation of CD16 expression during human NK cell development. J Immunol. 2018;200:565-72.

34. Thomas A, Rajan A, Szabo E, et al. A phase I/II trial of belinostat in combination with cisplatin, doxorubicin, and cyclophosphamide in thymic epithelial tumors: a clinical and translational study. Clin Cancer Res. 2014;20:5392-402.

35. Govindaraj $C$, Tan $P$, Walker $P$, et al. Reducing TNF receptor $2+$ regulatory $T$ cells via the combined action of azacitidine and the HDAC inhibitor, panobinostat for clinical benefit in acute myeloid leukemia patients. Clin Cancer Res. 2014;20:724-35.

36. Tao R, de Zoeten EF, Ozkaynak E, et al. Deacetylase inhibition promotes the generation and function of regulatory T cells. Nat Med. 2007;13:1299-307.

37. Shen L, Pili R. Class I histone deacetylase inhibition is a nove mechanism to target regulatory $T$ cells in immunotherapy. Oncoimmunology. 2012;1:948-50.

38. Kelly-Sell MJ, Kim YH, Straus S, et al. The histone deacetylase inhibitor, romidepsin, suppresses cellular immune functions of cutaneous T-cell lymphoma patients. Am J Hematol. 2012;87:354-60.
39. Zhu S, Denman CJ, Cobanoglu ZS, et al. The narrow-spectrum HDAC inhibitor entinostat enhances NKG2D expression without NK cell toxicity, leading to enhanced recognition of cancer cells. Pharm Res. 2015;32:779-92.

40. Ogbomo H, Michaelis M, Kreuter J, et al. Histone deacetylase inhibitors suppress natural killer cell cytolytic activity. FEBS Lett. 2007;581:1317-22.

41. Kim S, lizuka K, Aguila HL, et al. In vivo natural killer cell activities revealed by natural killer cell-deficient mice. Proc Natl Acad Sci U S A. 2000;97:2731-6.

42. Orange JS. Natural killer cell deficiency. J Allergy Clin Immunol. 2013;132: 515-25. quiz 26

43. Lopez-Soto A, Gonzalez S, Smyth MJ, et al. Control of metastasis by NK cells. Cancer Cell. 2017;32:135-54.

44. Cartron PF, Blanquart C, Hervouet E, et al. HDAC1-mSin3a-NCOR1, Dnmt3bHDAC1-Egr1 and Dnmt1-PCNA-UHRF1-G9a regulate the NY-ESO1 gene expression. Mol Oncol. 2013;7:452-63.

45. Nakashima H, Nguyen T, Chiocca EA. Combining HDAC inhibitors with oncolytic virotherapy for cancer therapy. Oncolytic Virother. 2015;4:183-91.

46. Mazzone R, Zwergel C, Mai A, et al. Epi-drugs in combination with immunotherapy: a new avenue to improve anticancer efficacy. Clin Epigenetics. 2017;9:59.

\section{Ready to submit your research? Choose BMC and benefit from:}

- fast, convenient online submission

- thorough peer review by experienced researchers in your field

- rapid publication on acceptance

- support for research data, including large and complex data types

- gold Open Access which fosters wider collaboration and increased citations

- maximum visibility for your research: over $100 \mathrm{M}$ website views per year

At BMC, research is always in progress.

Learn more biomedcentral.com/submissions 